\title{
6 Social acceptance and border control technologies
}

\author{
Simone Casiraghi, ${ }^{*}$. Peter Burgess ${ }^{* *}$ and Kristoffer Lidén ${ }^{* * *}$ \\ *Vrije Universiteit Brussel.E-mail: simone.casiraghi@vub.be. \\ ${ }^{*}$ École Normale Supérieure, Paris \& Vrije Universiteit Brussel. \\ E-mail: james.peter.burgess@ens.fr. \\ *** Peace Research Institute Oslo. E-mail: kristoffer@prio.org.
}

\subsection{Introduction}

\subsubsection{Definition of the social acceptance}

Social acceptance of technology is a concept that indicates the degree to which 'a new technology is accepted - or merely tolerated - by a community.' Acceptance, in turn, refers to the act of receiving something that is offered, of giving an affirmative reply to it, and accommodating to it with approval. ${ }^{2}$ In this sense, social acceptance differs from ethics and stakeholder involvement. To distinguish one from the other, ethics refers to a systematic reflection, a philosophical critique, and an evaluation of customs, habits and traditions in a given context. ${ }^{3}$ Therefore, while ethics is a normative concept, and as such requires mostly a desk-based research (although supplemented by stakeholder involvement), social acceptance, in turn, is a mainly empirical concept, and as such needs to be assessed on the basis of verifiable information or experience. ${ }^{4}$

Yet, the two concepts - social acceptance and ethics - are interrelated and complementary. What is portrayed as acceptable influences how people actually accept a technology. If, for example, the media say biometrics are acceptable despite the infringements of privacy and other fundamental rights, this narrative can have an influence upon how users actually come to accept them. Vice versa, the way some people react to a technology may change what they consider to be ethically acceptable: the fact that some activists protest 
against invasive surveillance methods, e.g. by covering their face in public spaces with a mask, can have an effect upon users that had not previously perceived a problem as having existed with such methods. On the one hand, a social acceptance assessment can help the assessors refine the list of arguments for the ethics assessment in Chapter 5. On the other, the recurring arguments included in the ethics assessment can act as an inspiration in the development of acceptance assessment techniques (e.g. formulating questions for questionnaires).

Social acceptance and stakeholder involvement are also distinct concepts. The basic idea of the two concepts is to allow for wider representation. In the context of impact assessment, this translates into allowing multiple stakeholders ${ }^{5}$ to participate in the assessment process, opening up the process beyond the team of assessors. Also, the list of techniques is, in principle, the same, and their choice depends on the timespan and resources available, and the goal of the assessment. The execution of the techniques and their scope, however, differs. Stakeholder involvement is a broader concept: the idea is to involve any stakeholder in order to allow them to have a say on (ideally) every specific phase of the process in a continuous, ongoing manner (e.g. types of risks, how to assess risks, result of the threshold analysis, recommendations, etc.). In the social acceptance assessment, the idea is to assess how a more limited group of pre-defined stakeholders accommodates or gives a positive reply to a given initiative at a specific point during the assessment process, i.e. Step 5 of the integrated impact assessment process (Appraisal of impacts).

Given these preliminary distinctions, the structure of the Chapter will be as follows: In the next sub-sections, some further introductory notions on social acceptance (its importance for society, historical development and literature review) and about the social acceptance component of the benchmark will be outlined, including its importance in the assessment process and the actors involved in it. Section 6.2 will provide the assessors with the key concepts critical in conducting the social acceptance steps of the impact assessment process according to the Template included in Annex 1. To do this, the perspectives, techniques and types of stakeholders, as well as common misconceptions about what social acceptance is about, are explored.

\subsubsection{The importance of social acceptance for society}

The introduction of new technologies to society can give rise to widespread adoption, but also to episodes of discomfort, denial or even social resistance. Classic examples of the latter include the construction of nuclear plants or chemical factories that led to local protests. ${ }^{6}$ In such cases, local communities might protest against top-down decisions that put their environment, health or local activities in danger. But similar episodes have happened with the introduction of surveillance and biometric technologies. For example, the EU-funded project iBorderCtrl (2016-2019), in which a 'smart' Automated Deception Detection System (ADDS) was being developed, was harshly criticised, by the press and 
some civil society organisations for, among other aspects, ${ }^{7}$ its scientific developments and possible discriminatory outcomes. ${ }^{8}$ From this it can be seen that sometimes technologies as such are not accepted by the public, even before the products are put on the market (e.g. during the research phase). In other cases, users do not adopt, or even actively 'resist', new technologies until after they are introduced to the market, or they simply express their fears about potential misuse. ${ }^{9}$

An example is the use of Live Facial Recognition (LFR) by the police in public spaces in the UK. A survey by the Ada Lovelace Institute, ${ }^{10}$ which was intended to assess the 'public attitudes' to LFR, showed some positive acceptance of the public towards its use. $70 \%$ of the respondents supported the use of LFR by police in criminal investigation, and 50\% supported its use in airports in place of passport control. ${ }^{11} \mathrm{~A}$ similar survey of the London Policing Ethics Panel ${ }^{12}$ showed how $57 \%$ of the respondents thought the use of LFR by the police was acceptable and $75 \%$ that it would make it easier for the police to catch criminals. ${ }^{13}$

The same research, however, also evidenced some tensions regarding the public attitude towards LFR in the UK. For instance, the report by the Ada Lovelace Institute shows how, of those interviewed, 36\% 'did not know anything about' LFR and $48 \%$ 'knew little about it. ${ }^{14}$ On the use of LFR, $61 \%$ were uncomfortable with its use on public transport, ${ }^{15}$ and the percentages of people wanting it to be deployed for purposes like tracking shopping behaviour, monitoring children at school or people at work were extremely low (below 10\%). ${ }^{16}$ Similarly, the survey of the London Policing Ethics Panel showed how, overall, $43 \%$ of the people surveyed did not think that police use of LFR was acceptable, and 50\% responded that it would not make them feel safer. ${ }^{17}$ Moreover, $41 \%$ reported that they saw it as being invasive of people's privacy ${ }^{18}$ and $81 \%$ responded that they believed the ways in which police collect personal data should be strictly controlled. ${ }^{19}$

Debates like the one on LFR have shown that taking into account a nuanced perspective of public perceptions of emerging technologies is relevant, even if the results on performance, reliability and cost efficiency are encouraging. Like in the UK, introducing surveillance technologies without a proper public consultation might raise public outrage and political criticism. ${ }^{20}$ Failing to take these considerations into account early on may give rise to negative impacts not only on policymakers and industries developing technologies (in regard to which strategies or products cannot be thoroughly implemented or delayed, or which image might suffer reputational damages), but also on the public, who may not be aware of how they work and their risks, may not trust the private sector, or may not unconditionally support their deployment.

\subsubsection{The role of social acceptance in the benchmark}

While there are already well-established forms of data protection impact assessment, privacy impact assessment and, to a lesser extent, ethics impact assessment, ${ }^{21}$ which together constitute the other components of the benchmark of the integrated impact assessment 
method, there is no such a thing as 'social acceptance impact assessment'. Incorporating social acceptance into an integrated assessment method for border control technologies has to date not been attempted.

The reasons for social acceptance being part of the integrated impact assessment method are complementary. First, the method broadens its scope beyond traditional methods of assessing legal and ethical aspects of emerging technologies (traditionally more expert-based) and opens up the debate to 'lay experts ${ }^{22}$ of the technology, especially travellers themselves.

Second, the concept of social acceptance can be, and has often been, interpreted in too narrow and instrumental a way, often as a way to self-legitimate a pre-defined technological program. ${ }^{23}$ Even when performed robustly, assessing only de facto acceptance of a given initiative (with a dedicated method) is insufficient. The mere fact that (some) travellers accept border technologies is not enough to deem them ethically desirable or legally compliant. Therefore, social acceptance is only one part of the quadripartite benchmark in the integrated impact assessment process.

\subsubsection{Historical development of social acceptance}

Social acceptance did not play an important role in the history of impact assessment, ${ }^{24}$ but the concept of social acceptance developed in several disciplines, most notably psychology, and has recently been studied extensively in relation to technologies. There are at least two main strands to consider:

A. Information Technology (IT) acceptance research: This strand has roots in psychology, sociology and Information Systems (IS) literature. The research carried out in this area stems from the idea that, while the presence of IT has increased dramatically in organisations since the 1980s, IT first needs to be accepted and used by employees to be beneficial for the same organisations. Explaining the mechanisms behind acceptance and usage of single technologies resulted in the creation of several theoretical models, which are nowadays used and refined in multiple domains like, among others, health IS, bioinformatics and social networking ${ }^{25}$ to predict the technological behaviour of certain users in a given context. ${ }^{26}$

B. Social acceptance of energy projects and other large-scale infrastructures: This strand stems from practical policy and risk management literature, and takes into account the acceptance of both policies and politically contentious technologies. Rather than focusing on organisations and their employees, the emphasis is on the impact of disruptive or risky technologies on local communities. In this sense, the concept has been widely used in a variety of fields since the 1980s (e.g. nuclear waste management or carbon capture and storage), but more recently it has become a crucial point of discussion in social sciences debates around renewable and wind energy. ${ }^{27}$ 


\subsubsection{The profile needed for assessing social acceptance}

Since social acceptance is not regulated by law, there are no formal bodies or institutions in charge of supervising or assessing social acceptance, which is predominantly an enterprise carried out by individual researchers or groups.

Even by restricting the analysis to the two strands outlined in Section 6.1.4, researchers on social acceptance will still be drawn from multiple domains. At the same time, there is no specific profession or role that manifests an expertise in social acceptance of border control technologies. This might create confusion when composing the team of assessors.

Differently from ethics, some 'hard skills' are needed to perform a social acceptance assessment, although the extent to which this is the case depends on the techniques that are selected, as some techniques may require greater levels of specialisation than others. Given the sources referred to in this Chapter, assessors with a background in psychology, social sciences and information studies would possess a robust set of quantitative and qualitative methodological skills for performing the assessment. Alternatively, or as a complement, having a background in the humanities is also useful, and more particularly in philosophy or law and technology (including criminology). These latter profiles, however, may need some more time to become acquainted with certain traditional stakeholder involvement techniques. ${ }^{28}$

As for the case of ethics, the team of assessors may have no persons able to carry out this part of the assessment process, or it may lack the possibility to hire extra personnel to execute it. This could mean two main things. First, it could be a good opportunity to encourage some members of the institution in charge of the assessment to acquire new expertise through, for example, training. Alternatively, it is a chance to open up the assessment process to stakeholder involvement, i.e. the team of assessors may organise events or sessions with external experts or members of the public who can provide relevant input or support in the social acceptance assessment.

\subsubsection{Literature overview}

Unlike personal data protection, privacy and ethics, social acceptance of technologies is neither a well-established (academic) field within a clear-cut academic discipline, nor does it have a tradition of dedicated methods and techniques in the context of impact assessment. Yet, established scientific methods for the assessment of social perceptions are of direct relevance. To give a short overview, the two strands identified in Section 6.1.4 can be related to the context of border control:

Information Technology (IT) acceptance research: The most commonly used models that promote this approach are the Technology Acceptance Model (TAM) ${ }^{29}$ and the Unified Theory of Acceptance and Use of Technology (UTAUT). ${ }^{30}$ The latter is inspired by the former, and many other models have been proposed in between. TAM and UTAUT were 
first developed to assess acceptance in IS, subsequently spreading to other field like health IS, bioinformatics and social networking. ${ }^{31}$ The main feature of TAM and UTAUT is that of predicting the intentions of a user in their use of a technology and explaining the subsequent usage behaviour. The basic methodological idea is that there are several constructs that determine usage and acceptance, such as perceived usefulness or ease of use, and that these can be studied empirically. Despite their success, such models have been simultaneously criticised for being both overly complicated and overly simplistic. They are deemed overly complicated because they take into account too many independent variables (or constructs) at once, without clearly defining the relationships between them, while they are deemed overly simplistic because they overlook the fact that group, social and cultural aspects also play a role in technology acceptance. ${ }^{32}$

Social acceptance of energy projects and other large-scale infrastructures: In the literature on social acceptance of technologies in the energy field, in particularly wind energy, ${ }^{33}$ it has been pointed out how social acceptance can be studied from the angles of three intertwined perspectives that touch upon different groups of stakeholders: ${ }^{34}$

1. A socio-political perspective related to policy and institutional frameworks and wider public opinions. This is social acceptance at the most general level, like that described in the surveys on LFR in Section 6.1.2.

2. A community perspective related to residents and local authorities living in the sites of energy projects. This is about acceptance by local stakeholders related to the initiative, such as residents and local authorities.

3. A market perspective related to the process of market adoption and innovation. This is not only about consumers (the more consumers accept, the more they are willing to switch to a new technology and buy), but also about investors and companies who develop technologies.

Drawing an analogy from the case of border control technologies, in the early 2000s, authorities and policymakers found little reason to consult the public, ${ }^{35}$ as there was nothing to debate and no opt-out from this large-scale experiment in the use of biometrics to manage mobility risks. ${ }^{36}$ When the European Commission (EC), and especially the Directorate-General for Migration and Home Affairs (DG HOME), ${ }^{37}$ started focusing on the societal dimension of security technologies, the industry's perspective played a major role: 'the problems associated to the societal acceptance of security technologies results in a number of negative consequences. For industry it means the risk of investing in technologies which are then not accepted by the public, leading to wasted investment. For the demand side it means being forced to purchase a less controversial product which however does not entirely fulfil the security requirements. ${ }^{38}$ More recently, the EU and DG Home have been promoting different initiatives to include various stakeholders, and not only practitioners and industry. ${ }^{39}$

When the focus on the market perspective prevails over the community perspective, the role of the wider public or specific communities could be reduced to that of being 
informed or 'convinced' that these border solutions are the best possible alternatives available. This is the case when passengers, for instance, are merely considered from the perspective of customer satisfaction when asked about emerging security technologies. ${ }^{40}$

To show the assessors that social acceptance plays an important role from all the three perspectives listed above, the next Section zooms in on some key concepts that will facilitate assessors' undertaking of the social acceptance assessment.

\subsection{Social acceptance concepts and misconceptions}

\subsubsection{What social acceptance is about}

This Section presents a list of social acceptance concepts that the assessors need to consider in the assessment process. The list is based on the current discussions in the academic domains identified in Section 6.1.

\subsubsection{Engagement vs deficit model}

In technology discourses, when social acceptance is considered merely as an obstacle to overcome and as a necessary condition to support innovation, it is often assumed that opposition to technologies is due to an ignorance about or lack of information as to the benefits of the specific technology. ${ }^{41}$ In studies of public understanding of science, this is referred to as the 'deficit model. ${ }^{42}$ The deficit model assumes that an individual does not accept a type of (border control) technology because they lack an awareness of the advantages that such technology offers, like security, efficiency or convenience. The public therefore needs to be 'educated' by experts to become aware of the technologies in question and to be steered to trust them. The idea is that only if the public is correctly informed, then it could understand the reasons behind the massive deployment of new border technologies. Relying on a deficit model could transform the acceptance assessment process into a mere self-legitimating exercise, in which acceptance is assumed beforehand, and not subjected to public scrutiny. Opposed to the deficit model, according to the 'engagement model', individuals are not only 'instructed' but involved in a dialogue with scientists and policy makers. ${ }^{43}$ The idea is to move the engagement 'upstream, ${ }^{44}$ take the lay knowledge of the citizens seriously, and possibly achieve a two-way dialogue between the latter and scientists.

The engagement model, however, has also its limits. Even when individuals are engaged, it is unclear whether they passively react to a pre-established political and technological agenda, or if instead they challenge the agenda itself. ${ }^{45}$ Engagement will always be somehow partial, as it is not possible to take all views into account from the start. Rather, engagement is a matter of trial and error. The goal is to conceive engagement as a way 'to make visible the invisible, to expose to public scrutiny the values, visions and assumptions that are usually hidden', which, in practice, involves asking questions like: 'Why this 
technology? Why not another? Who needs it? Who is controlling it? Who benefits from it? Can they be trusted? What will it mean for me and my family?' ${ }^{46}$

The fact that a technology is feasible does not necessarily mean that it is accepted or acceptable. Thus, questioning the very desirability of the technology's goals and values, as well as the interests it will serve, is essential. Asking about acceptance is not merely collecting preferences about one or another feature or about perception of risks, but it is about recognising the normative and political choices by which the debate is framed. ${ }^{47}$

\subsubsection{Three types of perspectives}

It was noted above (Section 6.1.6) how at least three perspectives from which to study social acceptance have been identified; i.e. socio-political, community and market. ${ }^{48}$ For a comprehensive assessment, the assessors must consider all three perspectives, and - at the very least - not focus exclusively on the market or socio-political perspective. In the context of border control, these three levels mean the following:

1. The socio-political acceptance is about the generic, aggregated acceptance of a border technology. It is about the attitude of the generic traveller who crosses a border crossing point. The assessors have already been warned about the possible pitfalls of an over-reliance on this level of analysis: there is no 'generic' traveller per se, but different travellers with competing interests and values. However, an analysis at this level could be a starting point from which to provide some preliminary input for the assessment, allowing the assessors to focus on more specific issues or groups.

2. The community acceptance is the one that probably goes most unnoticed in border control technologies. Per se, community acceptance refers to the acceptance of local stakeholders. In the context of border control, this concept could be extended not only to the specific sites where a technology is being tested or deployed (e.g. a specific land, air or sea border of a specific country), but also to the specific (vulnerable) groups on which this technology is tested. Since vulnerable communities, such as non-citizens, might not have access to resources and human rights protections, it is more difficult for them to have a choice or a say in (not) accepting border control technologies. In turn, it is 'easier' for local authorities to exploit the situation and test technologies on them. Some authors have argued how the deployment of automated decision systems for migration and asylum purposes can be seen as a 'human laboratory' of high-risk experiments in automated decision-making. ${ }^{49}$ Similar patterns have taken place in the EU, for instance in refugee camps at the EU's external borders, like in Greece or Italy, ${ }^{50}$ or elsewhere, such as in Canada. ${ }^{51}$

3. The market acceptance is about the market adoption of a particular technology. It has more to do with how end-users (e.g. border police) are able to 'switch' from more traditional to more innovative technological solutions and accept this change as beneficial for their operations. As for any EU-funded Horizon 2020 research projects, the market acceptance is related to the exploitation of projects' results, and could include 
the assessment of possible skills shortages (e.g. among border guards), inadequate finances (e.g. to buy the technologies or build the required infrastructure), traditional value chains that are less keen to innovate, incompatibility between parts of the technological system (e.g. for lack of standards), or mismatch between market needs and the solution. ${ }^{52}$

\subsubsection{Stakeholders}

Especially when the focus of social acceptance is on the socio-political and community perspectives, involving travellers is necessary to move to an upstream engagement model and avoid a deficit model of participation in which decisions are taken by experts and more powerful stakeholders (such as companies or governments). In fact, there are many different travellers to consider, each with local, regional and national conflicting interests and values. ${ }^{53}$ Among them, acceptance may vary greatly depending on the group considered, especially when it comes to border control technologies. An initial rule-of-thumb to guide the assessor would be to look at the traveller categories in the Schengen Borders Code ${ }^{54}$ which can be divided in two macro-categories: ${ }^{55}$

- European Union (EU)/European Economic Area (EEA)/Helvetic Confederation $(\mathrm{CH})$ citizens

- Non-EU/EEA/CH citizens, including the sub-categories:

- Refugees,

- Travellers on a Schengen Visa,

- Travellers with ETIAS travel authorisation,

- Family members of EU citizens, and

- Third country nationals enjoying the right of free movement under EU law.

At the community level, not only EU citizens but also non-EU and even non-citizens or refugees are considered when it comes to social acceptance, because the latter categories are particularly affected and are more vulnerable to the risks posed by border technologies. When it is not possible to engage with these categories, a valid alternative is to engage with their representatives or with civil society organisations that can give voice to their concerns (such as the NGOs that are part of the European Digital Rights (EDRi) network), or with institutions tasked with investigating issues relating to fundamental rights (such as the European Union Agency for Fundamental Rights (FRA)).

There are also other stakeholders to consider at the community and socio-political level when it comes to acceptance, however, especially border guards and customs officers who need to operate the technologies. Asking border guards and customs officers about the acceptance of technologies (e.g. whether they fear automated technologies would take their job away or whether they think such technologies would reduce their overall workload) is important, but should not substitute or be confused with the acceptance assessment of travellers. 
On the market level, at the very least, industrial stakeholders, scientific experts and policy makers need to be taken into consideration. Industrial stakeholders could include technology or security service developers and providers. Scientific experts include people from academia and research institutes with a wide range of expertise, from hard sciences and applied sciences, such as engineering and computer science, to humanities, such as law, political science or philosophy. Finally, policy makers also include legislators and representatives from EU bodies and agencies related to border control, such as the European Border and Coast Guard Agency (Frontex), the European Union Agency for the Operational Management of Large-Scale IT Systems in the Area of Freedom, Security and Justice (eu-LISA) or the EC's DG HOME.

\subsubsection{Techniques and disciplines for assessing social acceptance ${ }^{56}$}

In Section 6.1.2, surveys and questionnaires were given as examples of techniques for assessing acceptance and public attitudes toward a particular border control technology (LFR), but these techniques do not fit the different groups and perspectives detailed above in the same ways. In parallel, the same techniques can fit different levels of analysis, e.g. a questionnaire to assess market acceptance or socio-political acceptance.

Surveys fit the socio-political level. ${ }^{57}$ For instance, polls and questionnaires are very generic and give a useful and wide, but possibly superficial, input. Interviews, online platforms and study groups are also advisable, because they can provide more nuanced results, but can also take more time to undertake, require greater expertise to be correctly executed, and only allow the collection of a smaller sample (in the same amount of time, just a few people can be interviewed while hundreds are able to complete a questionnaire). When different groups of travellers are considered at the same time, they have the possibility to confront one another through methods like consultive groups, roundtables or workshops. To make the input of travellers more robust, participants could be asked to fill in questionnaires immediately after a facility tour or technology demonstration of the initiative under assessment (e.g. a video, a graphical representation, or simulation of a technology)..$^{58}$

For the community level, it is advisable to resort to interviews, focus groups, hotlines and consultive groups. These techniques allow the assessors to hear the personal stories of vulnerable people, and how each of them experiences their own individual challenges. This would involve the sharing of sensitive details, so it is advisable that formats where opinions can be given in an anonymised way, and without being revealed to a bigger group, be promoted. A questionnaire or survey would give overly generic results at this level, although it can be valuable to ensure anonymity if enough space is given to elaborate on specific questions (e.g. a preference for open-ended questions over close-ended ones, where the respondent can elaborate on their answer instead of picking from pre-selected options).

On the market level, the assessors need to bring together stakeholders with different background and interests, and make them confront one another. Therefore, a plethora of other methods are advisable, including the Delphi process, workshops, roundtables, 
scenario planning and/or advisory groups. ${ }^{59}$ Furthermore, surveys and focus groups for market research, or market validation questionnaires, provide a valid alternative if limited time and resources are available for the assessment process.

\subsubsection{What social acceptance is not about}

The concept of social acceptance is often accompanied by a number of key assumptions in the public debate that serve to limit its scope. Including social acceptance in an integrated assessment process allows the assessors to look critically at these assumptions, in order to help the assessors perform a robust social acceptance assessment. Some of these assumptions are listed below. ${ }^{60}$

'The majority of people support the technology': It is often emphasised in public surveys how support for border technologies or trust for authorities is high. The assumption of strong support and trust is then taken as a starting point for the discussion on the large-scale implementation of these technologies. Regardless of the fact of whether this has an empirical basis or not, a critical appraisal of these polls and surveys is sometimes lacking. Aspects to consider are, for instance:

- Who commissioned the poll, since a poll's goal and ultimate aim can be very different if it is commissioned by a company, a research consortium, a governmental organisation or an NGO. A company producing technologies might place more emphasis on the positive results of a survey for its economic advantage, while an NGO fighting for the respect of human rights might be more interested in stressing the negative results on vulnerable populations.

- How and by whom the questions are analysed, since depending on the message that one wants to convey with the results, certain relevant information might be underrated (for example the fact that awareness of how the technology works is very low), or certain not-so-relevant information overly emphasised. Findings can be presented as 'objective facts' that can be quantitatively measured, not worth discussing, although there are a variety of subjective factors at play that cannot simply be reduced to numeric values. ${ }^{61}$ Since the methods employed and the design of the study are decided beforehand, a bias to these can be introduced by the results that one wants to demonstrate.

- The point in time when the surveys were conducted, since the timeframe of the research can influence the results of a survey. If people are asked about the acceptance of a nuclear plant immediately before and immediately after a nuclear incident, like that at Chernobyl, the results obtained from the pool would show a huge contrast.

- The selection of the samples, to make sure that participants are selected in a representative way. If travellers were asked about a new technology introduced at an airport, the results would vary significantly if the interviewees were mostly white, European middle-aged men, with few women, elderly, people of colour or with disabilities being asked their opinions, to if the composition of the pool of those questioned were the other way round. 
'Social acceptance should be achieved for a greater goal': In political debates about technologies, there is often an assumption that social acceptance is an obstacle to overcome for the sake of another goal, be it innovation, industrial growth or public security. Accordingly, media and policy discourses 'impose' how technologies should be accepted at any cost for such greater goals.

One example is the 'biometrics imaginary' that was first recently created in the US, and subsequently in the EU. ${ }^{62}$ Especially in the wake of 9/11, a great number of initiatives were undertaken to increase security in the US and worldwide. Among these, interoperability efforts were taken as crucial to connect different databases and therefore fight terrorism (e.g. by sharing watchlists). Interoperability has been used in the collective imaginary as a crucial component of security, while cultural and legal barriers to its implementation needed to be overcome. In the EU, enhancement of border control and interoperability has been portrayed as a means by which to promote European integration, against potential threats coming from external borders. Another example, outside the EU, is the case of the establishment of an Israeli national biometric database, as a result of the controversial Israeli Biometric Project (IBP). ${ }^{63}$ The scope of the project was officially countering the forgery of ID cards and passports. Behind the official motivation, however, the idea was to create a national centralised biometric database to enhance surveillance. Despite the strong social resistance to the project, it was shown how a part of the Israeli press consistently constructed a legitimising discourse of threat to national security, portraying Israel as a vulnerable victim and 'others' (e.g. Iranians) as dangerous enemies. ${ }^{64}$ Motives to support the IBP included cultural motives central to Jewish-Israeli history. This allowed to create a convergence between two aspects of identity: a national, cultural Israeli identity and an administrative procedure of biometric identification.

'Opponents are ignorant': This argument assumes too hastily that any form of opposition equals ignorance or lack of expertise, and that the knowledge of experts is by definition more valuable than lay knowledge. It undermines legitimate forms of opposition that can stem from different reasonings than those of the purported advantages of the technology, for example a fear for the infringement of human rights (such as privacy) or other culture-specific motivations. In fact, an increased level of knowledge or education could lead to a lower level of acceptance for certain technologies. Getting to know how one's data are managed, how they are made interoperable and searchable, and how they could be misused or misinterpreted, might increase the opposition to privacy-intrusive technologies among the broader public. If people are unaware or ignorant, by contrast, they might more passively accept such a technology and believe the advantages that are advertised to them. Some objectors to these technologies appear highly informed, for example certain NGOs in Europe, like the EDRi network, which includes, among others, Statewatch, an NGO that has published extensively on security and border control.$^{65}$ Another famous case is that of the philosopher Giorgio Agamben, who, in 2004, having to travel to the US for a 
guest lecture on a visa, decided to cancel the journey because he refused to have his fingerprint taken upon arrival. ${ }^{66}$ Although some people do not accept border technologies, their position does not necessarily result from ignorance, and needs to be taken seriously in both public debate and policy choices.

'Opponents are threats': Opposition to border technologies is also equated with threat, and, in turn, acceptance is an 'antidote' to such threats. Some groups of the public are excluded from engagement not because of their lack of knowledge, but because of the perceived risks they can cause, for example, in relation to public security (terrorists, political protesters, or activists), public health or irregular migration. In the case of border control, the threats are represented by so-called 'high-risk' travellers, who also evoke fear amongst the population. High-risk travellers, the argument goes, do not accept these technologies since they aim to evade these stricter controls, while 'low-risk' passengers, the category within which the vast majority of travellers and EU citizens fall, will accept them for the sake of public security, health and convenience. This argument assumes that there is a clear-cut distinction between low-risk and high-risk, which is in turn equated with a collective identity of 'us' (i.e. low-risk) vs. 'them' (i.e. high-risk). ${ }^{67}$ While we tend to accept the technologies, they do not. However, the ways in which a person may end up being categorized as low or high risk are determined by opaque criteria that might reflect discriminatory biases of the designers and border guards, such as racial biases ${ }^{68}{ }^{6}$ The problem is that not all those who are labelled 'high-risk' are serious threats or potential terrorists, and therefore their reasons for not accepting technologies are grounded in bases other than evading stricter controls and pursuing their criminal intents.

'Acceptance is a matter of single technologies and individual users': In many studies on social acceptance of technology in the fields of psychology and IS studies, an implicit assumption exists that social acceptance is mostly (1) an issue of individual users, and (2) a matter of single technologies. ${ }^{69}$ These criticisms are also relevant to the case of border control technologies. Most individuals make judgements about technologies depending on perceived usefulness, motivations or expectations, but these are all conditional on social circumstances and cultural identities. ${ }^{70}$ For instance, in the case of the lie detector developed by the project iBorderCtrl, people from Western countries, who may be familiarised with lie detectors (e.g. from movies or books), could have, at first sight, few problems with them. However, the same might not apply to people whose way of communicating is different, for example when it is considered inappropriate to have eye contact with persons of the opposite sex. ${ }^{71}$ Secondly, it is misleading to consider technological artefacts in isolation, regardless of the socio-technical systems in which they are introduced and, in particular, regardless of the political and power relations that are at play. ${ }^{72}$ Acceptance in border control is never mere acceptance of an artefact that can make travellers and border guards' lives more (or less) easy, but acceptance of a political architecture, as well: these technologies have to be used to strengthen the external borders of the $\mathrm{EU}$ and to better control migration flows. 


\section{Endnotes}

1. Behnam Taebi, "Bridging the Gap between Social Acceptance and Ethical Acceptability," Risk Analysis 37, no. 10 (2017): 1817-27, https://doi.org/10.1111/risa.12734.

2. Susana Batel, Patrick Devine-Wright, and Torvald Tangeland, "Social Acceptance of Low Carbon Energy and Associated Infrastructures: A Critical Discussion," Energy Policy 58 (2013): 1-5, https://doi.org/10.1016/j.enpol.2013.03.018.

3. See Chapter 5 in this Volume.

4. Social acceptance also goes by the name of 'public acceptance' or 'societal acceptance.' The term 'social acceptance' was chosen for this Volume, due to the fact that it is in line with the EC's terminology and the literature overviewed.

5. See Chapter 2 in this Volume.

6. Ibo van de Poel, "A Coherentist View on the Relation Between Social Acceptance and Moral Acceptability of Technology," in Philosophy of Technology After the Empirical Turn, ed. Maarten Frassen, Pieter E. Vermaas, Peter Kroes, Anthoine W. M. Meijers (Springer, 2016) 178, https:// doi.org/10.1007/978-3-319-33717-3_11.

7. The project was also targeted as an example of (mis)information and (mis)communication, since some of the crucial deliverables of the project (e.g. those on ethics) were not made available to the public.

8. See, for instance, Daniel Boffey, "EU Border 'lie Detector' System Criticised as Pseudoscience," The Guardian, November 2018, https://www.theguardian.com/world/2018/nov/02/ eu-border-lie-detection-system-criticised-as-pseudoscience and Eleftherios Chelioudakis, "Greece: Clarifications Sought on Human Rights Impacts of IBorderCtrl," 2018, https://edri. org/our-work/greece-clarifications-sought-on-human-rights-impacts-of-iborderctrl/.

9. van de Poel, "A Coherentist View on the Relation Between Social Acceptance and Moral Acceptability of Technology."

10. "Beyond Face Value: Public Attitudes to Facial Recognition Technology," 2019. The Ada Lovelace Institute is an independent research institute and deliberative body whose mission is to ensure data and Artificial Intelligence work for people and society. It was established by the Nuffield Foundation, in collaboration with the Alan Turing Institute, the Royal Society and the British Academy in the UK. See https://www.adalovelaceinstitute.org/.

11. Ada Lovelace Institute.

12. The London Policing Ethics Panel is an independent panel established by the Mayor of London to give ethical advice on policing issues that may impact public acceptance. See http:// www.policingethicspanel.london/.

13. London Policing Ethics Panel, "Final Report on Live Facial Recognition," 2019.

14. Ada Lovelace Institute, "Beyond Face Value: Public Attitudes to Facial Recognition Technology", 5.

15. Ada Lovelace Institute, 9.

16. Ada Lovelace Institute, 13.

17. London Policing Ethics Panel, "Final Report on Live Facial Recognition", 20.

18. London Policing Ethics Panel, 21.

19. London Policing Ethics Panel, 27.

20. Silkie Carlo, Jennifer Krueckeberg, and Griff Ferris, "Face Off: The Lawless Growth of Facial Recognition in UK Policing," Big Brother Watch (2018): 56.

21. See Annex 3 in this Volume.

22. Simone van der Burg, "A Lay Ethics Quest for Technological Futures: About Tradition, Narrative and Decision-Making," NanoEthics 10, no. 3 (2016): 233-44, https://doi.org/10.1007/ s11569-016-0273-2. 
23. Mhairi Aitken, "Why We Still Don't Understand the Social Aspects of Wind Power: A Critique of Key Assumptions within the Literature," Energy Policy 38, no. 4 (2010): 1834-41, https://doi.org/10.1016/j.enpol.2009.11.060.

24. See Chapter 2 in this Volume.

25. Neil Charness and Walter R Boot, "Technology, Gaming, and Social Networking," in Handbook of the Psychology of Aging, ed. K Warner Schaie and Sherry Willis (San Diego: Academic Press, 2016), 389-407, https://doi.org/10.1016/B978-0-12-411469-2.00020-0.

26. Viswanath Venkatesh et al., "User Acceptance of Information Technology: Toward a Unified View," MIS Quarterly 27, no. 3 (2003): 425-78.

27. Yann Fournis and Marie José Fortin, "From Social 'Acceptance' to Social 'Acceptability' of Wind Energy Projects: Towards a Territorial Perspective," Journal of Environmental Planning and Management 60, no. 1 (2017): 1-21, https://doi.org/10.1080/09640568.2015.1133406.

28. See Annex 2 in this Volume.

29. Fred D Davis, "Perceived Usefulness, Perceived Ease of Use, and User Acceptance of Information Technology," MIS Quarterly 13, no. 3 (1989): 319-40, https://doi.org/10.2307/249008.

30. Venkatesh et al., "User Acceptance of Information Technology: Toward a Unified View."

31. Charness and Boot, "Technology, Gaming, and Social Networking."

32. Richard P. Bagozzi, "The Legacy of the Technology Acceptance Model and a Proposal for a Paradigm Shift," Journal of the Association for Information Systems 8, no. 4 (2007): 244-54, https://doi.org/10.17705/1jais.00122.

33. Ellis Geraint and Gianluca Ferrero, "The Social Acceptance of Wind Energy. Where We Stand and the Path Ahead," 2016, https://doi.org/10.2789/696070.

34. Rolf Wüstenhagen, Maarten Wolsink, and Mary Jean Bürer, "Social Acceptance of Renewable Energy Innovation: An Introduction to the Concept," Energy Policy 35, no. 5 (2007): 2683-91, https://doi.org/10.1016/j.enpol.2006.12.001.

35. Ben Hayes, "Arming Big Brother The EU's Security Research Programme," 2006; Ben Hayes, "NeoConOpticon. The EU Security-Industrial Complex," 2009.

36. Kristrun Gunnarsdóttir and Kjetil Rommetveit, "The Biometric Imaginary: (Dis)Trust in a Policy Vacuum," Public Understanding of Science 26, no. 2 (2017): 195-211, https://doi. org/10.13140/RG.2.1.4207.4325.

37. See, for example, how the promotion of the social acceptance of security technologies is one of the objectives aimed for in order to enhance the competitiveness of European industry: European Commission, Work Programme 2018-2020 'Secure societies - Protecting freedom and security of European citizens', Decision C(2020)1862.

38. European Commission, Security Industrial Policy. Action Plan for an innovative and competitive Security Industry, $\operatorname{COM(2012)~} 0417$ final, 5.

39. Examples include the 'Europe for Citizens Programme' and its funding streams (Council Regulation (EU) No 390/2014 of 14 April 2014 establishing the 'Europe for Citizens' programme for the period 2014-2020 OJ L 115, 17.4.2014, p. 3-13) and the 'Community of Users on Secure, Safe and Resilient Societies' (Philippe Quevauviller, ed., A Community of Users on Secure, Safe and Resilient Societies (1st edn, Publications Office of the European Union 2018)).

40. Leon Hempel et al., "Towards a Social Impact Assessment of Security Technologies: A Bottom-up Approach," Science and Public Policy 40, no. 6 (2013): 740-54, https://doi. org/10.1093/scipol/sct086.

41. See Section 6.2.2.

42. Rob Flynn, Risk and the Public Acceptance of New Technologies, ed. Rob Flynn and Paul Bellaby, Risk and the Public Acceptance of New Technologies (London: Palgrave Macmillan UK, 2007), https://doi.org/10.1057/9780230591288. 
43. Alan Irwin and Brian Wynne, "Introduction," in Misunderstanding Science?, ed. Alan Irwin and Brian Wynne (Cambridge: Cambridge University Press, 1996), 1-18, https://doi. org/10.1017/CBO9780511563737.001.

44. James Wilsdon and Rebecca Willis, See-Through Science: Why Public Engagement Needs to Move Upstream (London: Demos, 2004).

45. Melissa Leach, Ian Scoones, and Brian Wynne, eds., Science and Citizens. Globalization and the Challenge of Engagement (London \& New York: Zed Books, 2005).

46. Wilsdon and Willis, See-Through Science: Why Public Engagement Needs to Move Upstream.

47. Flynn, "Risk and the Public Acceptance of New Technologies".

48. Wüstenhagen, Wolsink, and Bürer, "Social Acceptance of Renewable Energy Innovation: An Introduction to the Concept."

49. Petra Molnar, EDRi, and the Refugee Law Lab, "Technological Testing Grounds. Migration Management Experiments and Reflections from the Ground Up," 2020.

50. Chris Jones, "Automated Suspicion: The EU's New Travel Surveillance Initiatives," 2020; Raphael Tsavkko Garcia, "How the Pandemic Turned Refugees Into 'Guinea Pigs' for Surveillance Tech," OneZero, 2021.

51. Petra Molnar and Lex Gill, "Bots at the Gate: A Human Rights Analysis of Automated Decision-Making in Canada's Immigration and Refugee System," International Human Rights Program \& Citizen Lab, 2018, 88.

52. See the entry 'Dissemination and exploitation of results' of the H2020 Online Manual: https://ec.europa.eu/research/participants/docs/h2020-funding-guide/grants/grant-management/dissemination-of-results_en.htm.

53. Flynn, "Risk and the Public Acceptance of New Technologies".

54. Regulation (EU) 2016/399 of the European Parliament and of the Council of 9 March 2016 on a Union Code on the rules governing the movement of persons across borders (Schengen Borders Code), OJ L 77, 23.3.2016, 1-52.

55. Ibid., 1-52.

56. See also Annex 2 in this Volume.

57. Surveys are conducted by trained interviewers who select a representative sample, ensure the questions are unbiased and formulated clearly, and take into account the statistical significance of the research. See James L. Creighton, The Public Participation Handbook: Making Better Decisions through Citizen Involvement (Jossey-Bass, 2005), 128; Louis M. Rea and Richard A. Parker, Designing and Conducting Survey Research. A Comprehensive Research Guide, Third (Jossey-Bass, 2005).

58. US Environmental Protection Agency, RCRA Public Participation Manual, 1996, 56. See also Annex 2 in this Volume.

59. For an overview of such methods, see Annex 2 in this Volume.

60. Adapted from Aitken, "Why We Still Don't Understand the Social Aspects of Wind Power: A Critique of Key Assumptions within the Literature."

61. Andrea Saltelli, "Ethics of Quantification or Quantification of Ethics?," Futures 116 (2020): 102509, https://doi.org/10.1016/j.futures.2019.102509.

62. Kjetil Rommetveit, "Introducing Biometrics in the European Union: Practice and Imagination," The International Library of Ethics, Law and Technology 17 (2016): 113-26, https://doi. org/10.1007/978-3-319-32414-2_8.

63. Avi Marciano, "The Discursive Construction of Biometric Surveillance in the Israeli Press: Nationality, Citizenship, and Democracy," Journalism Studies 20, no. 7 (2019): 972-90, https://doi.org/10.1080/1461670X.2018.1468723.

64. Marciano. 
65. Chris Jones, Jane Kilpatrick, and Mariana Gkliati, "Deportation Union: Rights, Accountability, and the EU's Push to Increased Forced Removals," 2020, https://www.statewatch.org/ deportation-union-rights-accountability-and-the-eu-s-push-to-increase-forced-removals Jones, "Automated Suspicion: The EU's New Travel Surveillance Initiatives," https://www.statewatch.org/media/1235/sw-automated-suspicion-full.pdf.

66. Giorgio Agamben, "Bodies Without Words: Against the Biopolitical Tatoo," German Law Journal 5, no. 2 (2004): 168-69.

67. Katja Franko Aas, “'Crimmigrant' Bodies and Bona Fide Travelers: Surveillance, Citizenship and Global Governance," Theoretical Criminology 15, no. 3 (2011): 331-46, https://doi. org/10.1177/1362480610396643.

68. Ruha Benjamin, Race After Technology: Abolitionist Tools for the New Jim Code (Cambridge, UK: Polity Press, 2019).

69. Bagozzi, "The Legacy of the Technology Acceptance Model and a Proposal for a Paradigm Shift."

70. Flynn, "Risk and the Public Acceptance of New Technologies".

71. Petra Molnar, "Emerging Voices: Immigration, Iris-Scanning and IBorderCTRL-The Human Rights Impacts of Technological Experiments in Migration" (OpinioJuris, 2019), http:// opiniojuris.org/2019/08/19/emerging-voices-immigration-iris-scanning-and-iborderctrl-the-human-rights-impacts-of-technological-experiments-in-migration/.

72. Molnar and Gill, "Bots at the Gate: A Human Rights Analysis of Automated Decision-Making in Canada's Immigration and Refugee System," https://citizenlab.ca/wp-content/uploads/2018/09/IHRP-Automated-Systems-Report-Web-V2.pdf. 